\title{
The United Kingdom public health response to an imported laboratory confirmed case of a novel coronavirus in September 2012
}

R G Pebody (Richard.Pebody@hpa.org.uk) ${ }^{1}$, M A Chand ${ }^{1}$, H L Thomas ${ }^{1,2,3}$, H K Green1, N L Boddington ${ }^{1}$, C Carvalho ${ }^{1,3}$, C S Brown ${ }^{1}$,

S R Anderson ${ }^{1}$, C Rooney ${ }^{1}$, E Crawley-Boevey ${ }^{1}$, D J Irwin'1, E Aarons ${ }^{4}$, C Tong ${ }^{4}$, W Newsholme ${ }^{4}$, N Price ${ }^{4}$, C Langrish ${ }^{4}$, D Tucker ${ }^{4}$,

H Zhao $^{1}$, N Phin ${ }^{1}$, J Crofts ${ }^{1}$, A Bermingham ${ }^{1}$, E Gilgunn-Jones ${ }^{1}$, K E Brown ${ }^{1}$, B Evans ${ }^{1}$, M Catchpole ${ }^{1}$, J M Watson ${ }^{1}$

1. Health Protection Agency (HPA), London, United Kingdom

2. Field Epidemiology Training Programme (FETP), Health Protection Agency, London, United Kingdom

3. European Programme for Intervention Epidemiology Training (EPIET), European Centre for Disease Prevention and Control, (ECDC), Stockholm, Sweden

4. Guy's and St Thomas' NHS Foundation Trust and King's Health Partners, London, United Kingdom

Citation style for this article:

Pebody RG, Chand MA, Thomas HL, Green HK, Boddington NL, Carvalho C, Brown CS, Anderson SR, Rooney C, Crawley-Boevey E, Irwin DJ, Aarons E, Tong C, Newsholme W, Price N, Langrish C, Tucker D, Zhao H, Phin N, Crofts J, Bermingham A, Gilgunn-Jones E, Brown KE, Evans B, Catchpole M, Watson JM. The United Kingdom public health response to an imported laboratory confirmed case of a novel coronavirus in September 2012. Euro Surveill. $2012 ; 17(40)$ :pii=20292.

Available online: http://www.eurosurveillance.org/ViewArticle.aspx?Articleld=20292

On 22 September 2012, a novel coronavirus, very closely related to that from a fatal case in Saudi Arabia three months previously, was detected in a previously well adult transferred to intensive care in London from Qatar with severe respiratory illness. Strict respiratory isolation was instituted. Ten days after last exposure, none of 64 close contacts had developed severe disease, with 13 of 64 reporting mild respiratory symptoms. The novel coronavirus was not detected in 10 of 10 symptomatic contacts tested.

The outbreak of Severe Acute Respiratory Syndrome (SARS) in 2003, which led to 8,422 cases and 916 deaths worldwide [1], highlighted the potential for newly emerging zoonotic coronaviruses to transmit from person to person, especially in healthcare settings, and to cause severe human illness.

On 22 September 2012, the Health Protection Agency (HPA) in London, United Kingdom (UK), confirmed infection with a novel coronavirus in a patient in a London hospital who had been transferred from Qatar 11 days previously. This patient represents the second confirmed case of severe acute respiratory illness caused by this novel coronavirus. The first case was identified in a Saudi Arabian national who died in June $2012[2,3]$. We describe the exposure history, the public health response and follow-up of close contacts of the case in London.

\section{Case exposure history and}

\section{laboratory investigations}

The case is a previously well 49 year-old male, who travelled to Saudi Arabia from 31 July to 18 August 2012, where he, and several of his travelling companions, developed rhinorrhoea and fever (Figure 1). On 18 August he travelled to Qatar, where his respiratory symptoms resolved three days later. While in Qatar, he spent time on a farm, where he keeps camels and sheep, although no direct contact with these animals was reported.

On 3 September, he reported a mild respiratory illness. Six days later, he required hospitalisation due to development of bilateral pneumonia. His condition worsened and he subsequently required intubation and ventilation. On 12 September, he was transferred by air ambulance to an intensive care unit in London, where acute renal impairment was also detected. Due to further deterioration, he was transferred to another London hospital on 20 September [3].

Following the report on proMED on 20 September 2012 [2] of the detection of a novel coronavirus (until further taxonomic denomination herewith referred to as h(oV-EMC) in a Saudi Arabian patient who had died from severe respiratory illness and renal failure, and as no diagnosis had been established despite investigations for common causes of pneumonia and pathogens endemic to the Middle East, the patient in London was investigated for novel coronavirus infection. On 21 September, a coronavirus was detected in respiratory tract samples using a pan-coronavirus PCR assay, and on 22 September sequencing of the PCR amplicon showed a sequence very closely related to the hCoVEMC detected in the earlier patient from Saudi Arabia [4]. The virus belongs to the genus beta-coronavirus, with closest relationship to bat coronaviruses [4].

\section{Public health management}

The identification of a novel coronavirus of the same group as the SARS-CoV, with two clinically severe human cases including one fatality, led to a public health response being mounted to isolate the case, 
Timeline of disease and travel history of novel coronavirus case, London, August-September 2012

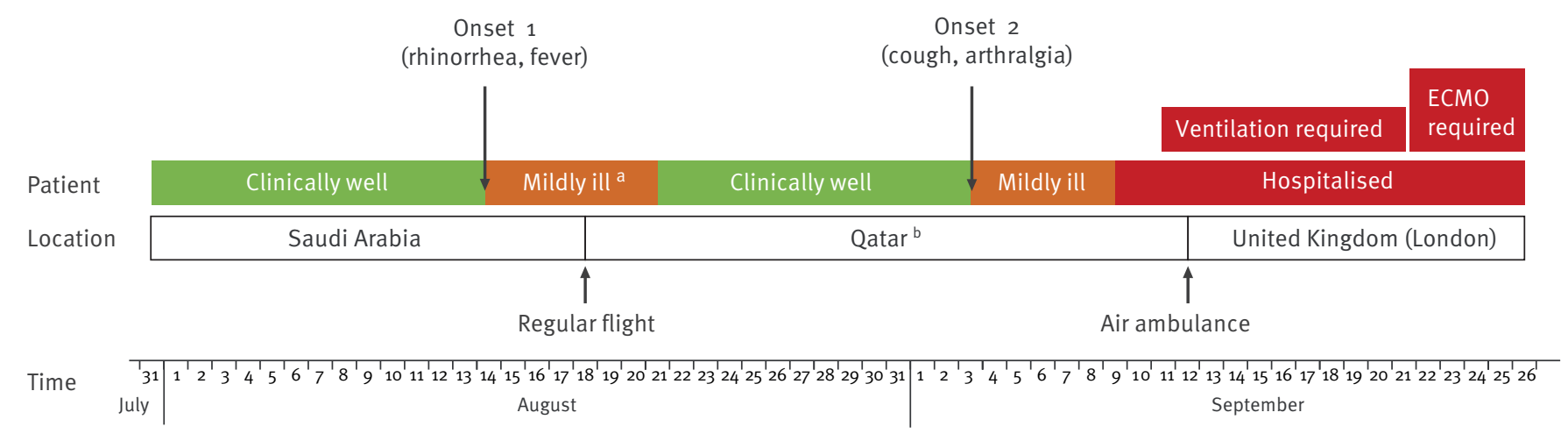

ECMO: Extracorporeal Membrane Oxygenation.

${ }^{a}$ According to relatives of the patient.

${ }^{\mathrm{b}}$ Contact with farm animals during stay (camels, sheep).

identify and test close contacts and to prevent onward transmission. Once the patient was found to have a novel coronavirus infection, he was isolated in a negative-pressure single room, and full personal protective equipment (PPE), including gowns, gloves, eye protection and high filtration masks were worn by staff and other contacts. Interim case and close contact definitions were developed [5].

A possible case was defined as any person with acute respiratory syndrome which includes fever ( $\geq 38^{\circ} \mathrm{C}$ ) or history of fever and cough requiring hospitalisation or with suspicion of lower airway involvement (clinical or radiological evidence of consolidation) not explained by another infection or aetiology with history of either travel to or residence in Saudi Arabia or Qatar or close contact with a confirmed case in the ten days before onset of illness

\section{A close contact was defined as the following persons}

- Healthcare and social care workers: worker who provided direct clinical or personal care or examination of a symptomatic confirmed case or within close vicinity of an aerosol generating procedure AND who was not wearing full personal protective equipment (PPE) at the time. Full PPE is defined as correctly fitted high filtration mask (FFP3), gown, gloves and eye protection.

- Household: any person who has had prolonged faceto-face contact with the confirmed case(s) any time during the illness after onset in a household setting.

- Other close contacts: any person who has had prolonged face-to-face contact with a confirmed case while symptomatic in any other enclosed setting and not wearing a mask e.g. school, visitor to the hospital to the bed side of a symptomatic confirmed case.
These definitions were used as the basis for identifying further possible cases and contacts. Guidelines were developed on the investigation and public health management of these cases and their close contacts.

Identification and follow-up of individuals who had close contact with the case at any time during his symptomatic period from entry into the UK up until implementation of full isolation on 21 September (including healthcare workers and family), was rapidly initiated by HPA staff and staff from the London hospitals' Infection Control Teams. Close contacts were followed up for a period of 10 days since the date of last exposure to the index case. If contacts developed respiratory illness in this period, they were asked to self-isolate in their homes (or were isolated in hospital if requiring admission).

The hospital in Qatar was informed to allow them to initiate appropriate follow-up for those who had been in contact with the patient.

HPA rapidly developed and published advice to health professionals, the public and travellers [5]. The case was immediately reported under the International Health Regulations to the World Health Organisation and through the European Union Early Warning and Response System (EWRS). Extensive laboratory work was undertaken to characterise the virus and develop new diagnostic tools [3].

\section{Initial epidemiological investigation and preliminary findings}

Close contacts of the case were followed up to determine the transmissibility of this novel coronavirus. This included collection of information on clinical illness, virological swabbing of contacts they had 
Outcome of close contact follow-up ten days or more since last exposure to index case with a novel coronavirus infection, London, September 2012 ( $\mathrm{n}=64)$

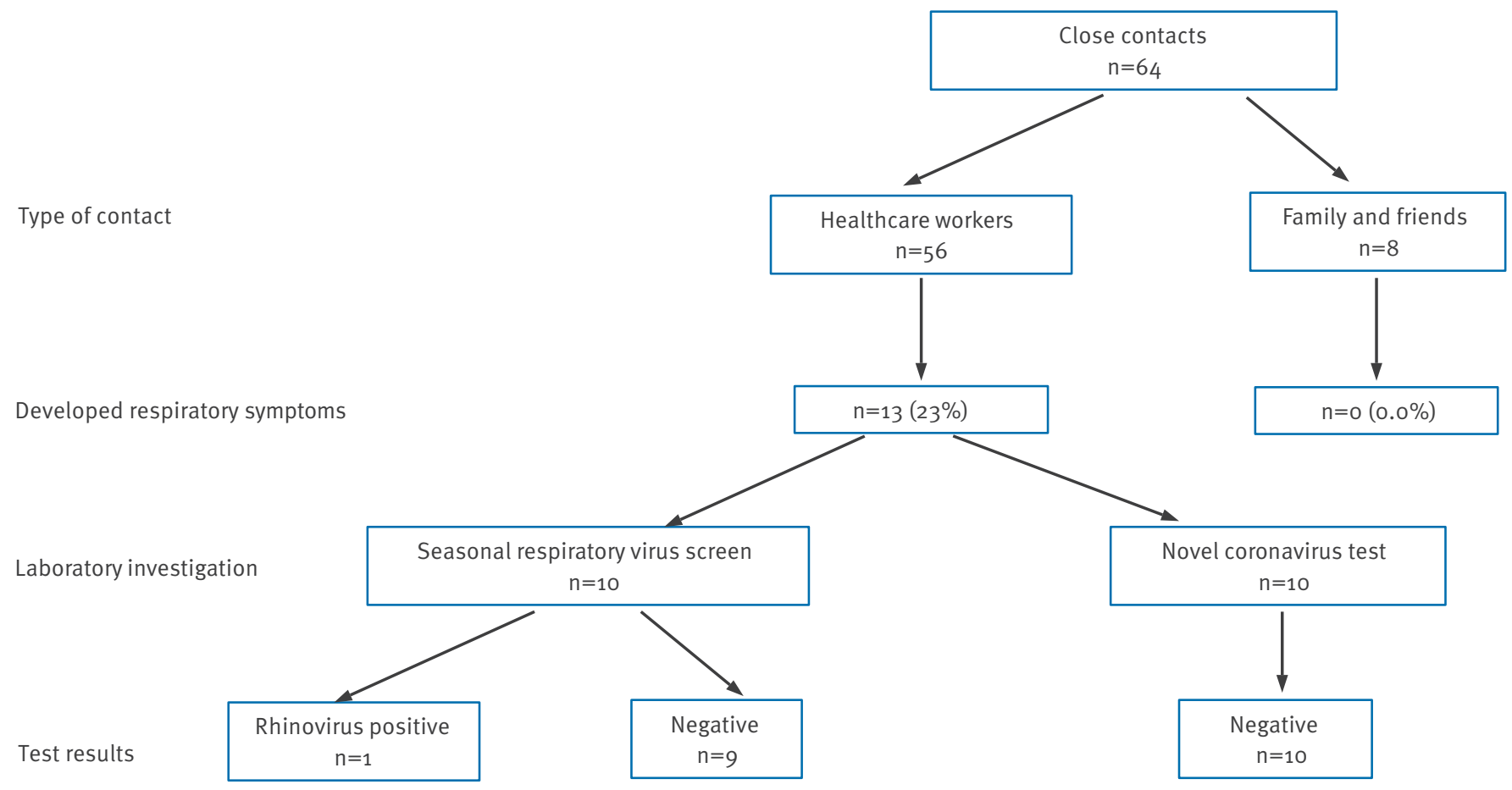

respiratory symptoms and collection of paired sera from all contacts to determine if there was evidence of recent infection.

It is likely that the patient's infection was acquired in Qatar as he was in Qatar for the 16 days prior to the onset of his most recent respiratory illness in September. The earlier mild upper respiratory tract infection, which began during his visit to Saudi Arabia, resolved two weeks before onset of the present illness.

By 4 October, tracing of contacts had identified 64 persons, among healthcare workers, family and friends, who were reported to have been in close contact with the confirmed case while he was symptomatic in the UK (Figure 2). Ten days after the date of last respective exposure, none of the close contacts had developed severe respiratory disease requiring hospital admission. Interim results have identified thirteen close healthcare worker contacts with mild, self-limiting respiratory symptoms. These contacts were self-isolated in their homes until asymptomatic. In addition, one hospitalised patient who had potential contact with the case and subsequently became unwell was identified and subsequently tested negative using a pancoronavirus assay [4]. The novel coronavirus has not been detected in any of the ten symptomatic healthcare worker contacts tested by 4 October 2012.

Four possible cases with a history of recent travel from Saudi Arabia or Qatar have also been identified and investigated in the UK since active case finding was commenced. Although the likelihood of novel coronavirus infection in any of these was considered low, strict infection control measures were taken. For three of them, samples were available and the novel coronavirus was not detected. A fourth case, who died at the beginning of September, remains under investigation.

\section{Public health implications}

We present a case of severe respiratory illness resulting from a novel coronavirus acquired in the Middle East. The clinical picture is similar to that of a case previously described from Saudi Arabia and caused by a closely related virus. Although cases of SARS, for which the causative agent SARS-CoV is in the same group of coronaviruses, were reported with incubation periods beyond 10 days, $95 \%$ were reported to have an incubation period of less than 10 days [6]. In the light of this, the case of novel coronavirus that we report appears to have been acquired in Qatar based on the known time course of the patient's infection and other 
available information, unless the illness had an unusual biphasic nature or a very long incubation period.

After 10 days of follow-up, there has been no confirmed evidence of ongoing person-to-person transmission resulting in severe disease or milder laboratory confirmed infection among close contacts, despite extensive active contact tracing. Completion of case-contact investigation, including serological testing when available, will determine whether mild or asymptomatic infection among close contacts has occurred. In addition, serological investigation in the countries of origin of the two confirmed cases should be considered to look for evidence of possible previous infection in the general population. Studies in animals are also necessary to determine whether there is an animal reservoir for this infection and what it might be.

Early detection and investigation of cases of severe respiratory illness among travellers returning from countries where infection with novel coronavirus has been reported and their close contacts will support the further elucidation of the epidemiological characteristics of this novel virus. An outbreak of severe respiratory illness of unknown aetiology was reported from the Middle East earlier in 2012 [7]. Work needs to be undertaken to determine if a novel coronavirus has been circulating more widely in the general population in the Middle East already for some time or if the virus was more recently introduced from an unknown animal reservoir.

\section{References}

1. World Health Organization (WHO). WHO final summary SARS, 15 August 2003: Summary table of SARS cases by country, 1 November 2002 - 7 August 2003. Geneva; WHO; 2003. Avaliable from: http://www.who.int/csr/sars/ country/2003_08_15/en/index.html

2. ProMED-mail. Novel coronavirus - Saudi Arabia: human isolate. Archive Number: 20120920.1302733 . September 20 September 2012. Available from: http://www.promedmail. org/? $\mathrm{p}=2400: 1000$

3. Corman VM, Eckerle I, Bleicker T, Zaki A, Landt O, EschbachBludau M, et al. Detection of a novel human coronavirus by real-time reverse-transcription polymerase chain reaction. Euro Surveill. 2012;17(39):pii=20285. Available from: http:// www.eurosurveillance.org/ViewArticle.aspx?Articleld $=20285$

4. Bermingham A, Chand MA, Brown CS, Aarons E, Tong C, Langrish C, et al. Severe respiratory illness caused by a novel coronavirus, in a patient transferred to the United Kingdom from the Middle East, September 2012. Euro Surveill. 2012;17(40):pii=20290. Available from: http://www. eurosurveillance.org/ViewArticle.aspx?Articleld=20290

5. Health protection Agency (HPA). Algorithm for investigation and management of possible cases of severe acute respiratory illness associated with a novel coronavirus. London; HPA; 2012. Available from: http://www.hpa.org.uk/webw/ HPAweb\&Page\&HPAwebAutoListName/Page/1317136202637

6. Lessler J, Reich NG, Brookmeyer R, Perl TM, Nelson KE, Cummings DA. Incubation periods of acute respiratory viral infections: a systematic review. Lancet Infect Dis. 2009; 9(5):291-300.

7. European Centre for Disease Prevention and Control (ECDC) Communicable Disease Threats Report (Week 18, 29 April-5 May 2012). Stockholm: ECDC; 2012. Available from: http:/ ecdc.europa.eu/en/publications/Publications/CDTR\%20 online\%20version \%204\%20May\%202012.pdf 